\title{
David Oliver: Are we seeing value based rationing clearly?
}

\section{David Oliver consultant in geriatrics and acute general medicine}

Berkshire

Leaders of public healthcare systems must make tricky decisions about prioritising resources, and they need public and professional engagement for this difficult role. Even a deluge of extra funding, after a relative drought of flat increases, wouldn't magically wash away this need, but a recent report by the Medical Technology Group left me wondering whether England's NHS is getting it right.

The report examined rationing of elective cataract surgery, using data from freedom of information requests sent to clinical commissioning groups (CCGs) in England. In total, 104 groups included elective cataract surgery on their list of "procedures of limited clinical value." 1 Of these, 76 used a "visual acuity threshold" before patients could be considered for cataract surgery, meaning that surgery is considerably delayed or not currently offered. A previous Royal College of Ophthalmologists survey reported that around two thirds of eye departments had moderate visual acuity thresholds to ration the procedure. ${ }^{2}$

In response to the Medical Technology Group's report, the umbrella body NHS Clinical Commissioners said that its member organisations had to make "tough choices": implementing the National Institute for Health and Care Excellence's (NICE) guidelines was "not mandatory." Guardian reported that 95 CCGs now restrict hernia repair, and 78 restrict elective hip and knee replacements. ${ }^{1}$ But cataract replacements provide a good lens for the broader issue.

Unwarranted variation in surgery rates should be explored using approaches such as Getting it Right First Time. ${ }^{5}$ But cataract surgery is not high cost per patient (although around 400000 people a year undergo it) ${ }^{4}$ : the NHS tariff prices it at $£ 667$ to $£ 1363$, depending on the procedure. ${ }^{6}$ In addition to its effects on the lives of people with worsening vision, delays in cataract surgery have been shown to increase the risk of falls and injuries, which carry their own costs to patients and services. ${ }^{7}$

NICE guidelines ${ }^{8}$ don't advocate rationing or restricting cataract surgery on the basis of visual acuity, and the Royal College of Ophthalmologists has criticised using visual acuity thresholds to decide rationing. ${ }^{9} \mathrm{NICE}$ states that cataract surgery is "one of the ways in which the NHS can transform our lives."
Although NICE is sometimes criticised for recommending treatment the NHS can't afford or implement, cost utility and cost effectiveness are built into its methods. Its recommendations can be challenged by judicial review, and CCGs can be challenged in the courts for failing to provide NICE standards of care. ${ }^{11}$

The policy emphasis on "value based" healthcare is growing, where value is defined in terms of spending on outcomes that matter to patients. ${ }^{12}$ Initiatives such as Choosing Wisely, Realistic Medicine, and Prudent Healthcare are embracing this approach. $^{13-15}$

I don't perceive that the NHS's mechanisms and joined-up policy have caught up with its ambitions around value based healthcare. In a whole range of treatments or services, we haven't consistently studied, measured, or described the outcomes that matter to patients, so we lack the tools for the job.

We haven't seen enough political accountability, public consultation, involvement, or oversight in rationing decisions. And, for elective procedures such as cataract surgery-which don't always offer the degree of benefit patients might hope for but can also transform their lives-we surely need informed, shared decision making based on conversations with individual patients, not the crude mechanisms of blanket bans and arbitrary cut-offs.

\section{Competing interests: See bmj.com/about-bmj/freelance-contributors.}

Provenance and peer review: Commissioned; not externally peer reviewed.

Campbell D. NHS England restricts patients' access to cataract removal. Guardian 2019 Mar 20. https://www.theguardian.com/politics/2019/mar/20/nhs-england-restricts-patientsaccess-to-cataract-removal.

2 Royal College of Ophthalmologists. $66 \%$ of clinical leads surveyed by the RCOphth confirm cataract rationing is restricting access to surgery. 9 Nov 2017. https://www.rcophth.ac.uk/ 2017/11/cataract-rationing-survey-reveals-66-of-responding-eye-units-have-somerestrictions-to-access-surgery/.

3 MacLeod A. NHS hospitals continue to restrict access to cataract surgery. Penningtons Manches. 9 Apr 2019. https://www.penningtons.co.uk/news-publications/latest-news/2019/ nhs-hospitals-continue-to-restrict-access-to-cataract-surgery/.

4 Smyth C. Elderly go blind as NHS ignores eye surgery rationing advice. Times 2019 Apr 6. https://www.thetimes.co.uk/edition/news/elderly-go-blind-as-nhs-ignores-eye-surgeryrationing-advice-bp5x77t0g. 
5 Royal College of Ophthalmologists. Getting it right first time for ophthalmology. 26 Feb 2017. https://www.rcophth.ac.uk/2017/02/getting-it-right-first-time-for-ophthalmology/.

6 NHS England. 2019/20 national tariff payment system. https://www.england.nhs.uk/paysyst/national-tariff/2019-20-payment-reform-proposals/.

7 Harwood RH, Foss AJE, Osborn F, Gregson RM, Zaman A, Masud T. Falls and health status in elderly women following first eye cataract surgery: a randomised controlled trial. Br J Ophthalmol 2005;89:53-9. https://bjo.bmj.com/content/89/1/53.

10.1136/bjo.2004.049478 15615747

8 NICE. Cataracts in adults: management. NICE guideline [NG77]. Oct 2017. https://www. nice.org.uk/guidance/ng77/chapter/Recommendations.

Royal College of Ophthalmologists. The way forward: cataract. 2017. https://www.rcophth ac.uk/wp-content/uploads/2015/10/RCOphth-The-Way-Forward-Cataract-300117.pdf.

10 Peninsula NHS Treatment Centre. NICE guidance on cataracts-base it on patient need, not eye tests. http://www.peninsulatreatmentcentre.nhs.uk/news/nice-guidance-oncataracts-base-it-on-patient-need-not-eye-tests/.
11 Edwards N, Appleby J, Timmins N. NICE at 20. BMJ 2019;364:11343. 10.1136/bmj.l1343 30957766

12 Anand JK. Electronic response to Gray M. Value based healthcare. BMJ 2017. https:// www.bmj.com/content/356/bmj.j437/rapid-responses.

13 Choosing UK. https://www.choosingwisely.co.uk/i-am-a-clinician/recommendations/.

14 Prudent Healthcare. Securing health and well-being for future generations. 2016. http:// www.prudenthealthcare.org.uk/wp-content/uploads/2016/02/Securing-Health-andWellbeing-for-Future-Generations1.pdf.

15 NHS Inform. Realistic medicine. 2018. https://www.nhsinform.scot/care-support-and-rights/ nhs-services/using-the-nhs/realistic-medicine.

Published by the BMJ Publishing Group Limited. For permission to use (where not already granted under a licence) please go to http://group.bmj.com/group/rights-licensing/ permissions 